\title{
Rapid detection of Echinococcus species by a high-resolution melting (HRM) approach
}

Guilherme Brzoskowski Santos ${ }^{1}$, Sergio Martín Espínola ${ }^{2}$, Henrique Bunselmeyer Ferreira ${ }^{1,3}$, Rogerio Margis ${ }^{1,3}$ and Arnaldo Zaha ${ }^{1,2,3^{*}}$

\begin{abstract}
Background: High-resolution melting (HRM) provides a low-cost, fast and sensitive scanning method that allows the detection of DNA sequence variations in a single step, which makes it appropriate for application in parasite identification and genotyping. The aim of this work was to implement an HRM-PCR assay targeting part of the mitochondrial cox1 gene to achieve an accurate and fast method for Echinococcus spp. differentiation.

Findings: For melting analysis, a total of 107 samples from seven species were used in this study. The species analyzed included Echinococcus granulosus $(n=41)$ and Echinococcus ortleppi $(n=50)$ from bovine, Echinococcus vogeli $(n=2)$ from paca, Echinococcus oligarthra $(n=3)$ from agouti, Echinococcus multilocularis $(n=6)$ from monkey and Echinococcus canadensis $(n=2)$ and Taenia hydatigena $(n=3)$ from pig. DNA extraction was performed, and a 444-bp fragment of the cox1 gene was amplified. Two approaches were used, one based on HRM analysis, and a second using SYBR Green Tm-based. In the HRM analysis, a specific profile for each species was observed. Although some species exhibited almost the same melting temperature $(T \mathrm{~m})$ value, the HRM profiles could be clearly discriminated. The SYBR Green Tm-based analysis showed differences between E. granulosus and E. ortleppi and between E. vogeli and E. oligarthra.
\end{abstract}

Conclusions: In this work, we report the implementation of HRM analysis to differentiate species of the genus Echinococcus using part of the mitochondrial gene cox1. This method may be also potentially applied to identify other species belonging to the Taeniidae family.

Keywords: Echinococcus species, High-resolution melting (HRM), Genotyping

\section{Findings}

The cyclophyllidean family Taeniidae is generally accepted to be composed of two valid genera, Taenia Linnaeus, 1758 and Echinococcus Rudolphi, 1801. Currently, there are nine recognized species within the genus Echinococcus, and four of them have medical significance: Echinococcus multilocularis, Echinococcus granulosus, Echinococcus oligarthra and Echinococcus vogeli [1]. The taxonomic position of $E$. granulosus has been recently revised, and species status was attributed to some of its 10 genotypes (G1-G10): E. granulosus sensu stricto (G1-G3),

\footnotetext{
*Correspondence: zaha@cbiot.ufrgs.br

'Programa de Pós-Graduação em Biologia Celular e Molecular, Universidade Federal do Rio Grande do Sul, Caixa Postal 15005, CEP 91501-970, Porto Alegre, RS, Brazil

${ }^{2}$ Programa de Pós-Graduação em Genética e Biologia Molecular, Universidade Federal do Rio Grande do Sul, Caixa Postal 15053, CEP 91501-970, Porto Alegre, RS, Brazil

Full list of author information is available at the end of the article
}

E. equinus (G4), E. ortleppi (G5), and E. canadensis (G6-G10) [2]. Another two species are now included in the Echinococcus genus, E. shiquicus and E. felidis $[3,4]$. Additionally, many of these species coexist in the same area, as is the case for E. granulosus and $E$. ortleppi and for E. oligarthra and E. vogeli $[5,6]$. The genus Taenia consists of approximately 50 species that are difficult to identify. Most of these are of medical and veterinary importance and lead to systemic (cysticercosis and coenurosis) and intestinal infections (taeniasis) $[7,8]$.

As a genotyping tool, the high-resolution melting (HRM) method has been used for the rapid differentiation of influenza A subtypes, for identification of the Cryptococcus neoformans-Cryptococcus gatti complex, and for parasites of the phylum Platyhelminthes and Protozoa [9-13]. For Trypanosoma cruzi, the HRM method has been implemented based on the amplification of a 383-bp 
DNA fragment of the cytochrome b gene (cyt b), allowing the effective differentiation of 14 genotypes and showing that the use of amplicons derived from mitochondrial genes is reliable and sufficiently robust for use in HRM [14].

The aim of this work was to develop an HRM-PCR assay targeting part of the mitochondrial cox1 gene to achieve a rapid, accurate, and low cost diagnostic method for detecting species belonging to the Echinococcus genus. In this work, we report the successful implementation of HRM analysis to differentiate species of the genus Echinococcus using part of the mitochondrial cox1 gene.

A total of seven species belonging to the Taeniidae family were used in this study (Table 1). The DNA extraction of E. granulosus and E. ortleppi was performed from protoscoleces, using proteinase $\mathrm{K}$, and from germinal layer $[5,15]$. DNA samples from the remaining species were obtained using the PureLinkTM Genomic DNA Kit (Invitrogen, USA), following the manufacturer's instructions.

A 444-bp fragment of the cytochrome c oxidase subunit I (cox1) gene [16], was amplified using the primers 5' -TTTTTTGGGCATCCTGAGGTTTAT-3' (forward) and 5'-TAAAGAAAG AACATAATGAAAATG-3' (reverse) in the following reaction mixture: 50 ng of DNA template, $5 \mathrm{mM}$ dNTP, 5 pmol of each primer, $1.2 \mathrm{mM} \mathrm{MgCl}_{2}, 1 \mathrm{U}$ Taq polymerase (Invitrogen, USA), $20 \mathrm{mM}$ Tris- $\mathrm{HCl}$ $(\mathrm{pH}$ 8.4), $50 \mathrm{mM} \mathrm{KCl}$, in a total volume of $20 \mu \mathrm{L}$. The PCR reactions were performed in a 7500 thermal cycler (Applied Biosystems) under primer annealing touchdown strategy [17]. All PCR reactions were carried out in technical triplicates with non-template controls (NTCs).

In an attempt to discriminate and accurately identify differences in all seven species, we used two approaches. SYBR Green Tm-based analysis, in which the dissociation step was obtained from the 7500 Applied Biosystems machine (with SDS software) using 1X SYBR green dye (Invitrogen, USA) and increasing the temperature from $60^{\circ} \mathrm{C}$ to $95^{\circ} \mathrm{C}$ at ramping increments of $0.2^{\circ} \mathrm{C} / \mathrm{s}$
(Table 1). A second approach employed the HRM technique (Table 1), that was carried out with SYTO 13 (Life technologies), a DNA dye that does not preferentially bind to GC- or AT-rich sequences, does not increase the melting temperature, and has a minimal inhibitory effect on PCR [18,19], at a $2.5 \mu \mathrm{M}$ final concentration, in a final volume of $10 \mu \mathrm{L}$, using the Eco Real-Time PCR System (Illumina ${ }^{\circ}$ ). In this assay, melting was conducted by increasing the temperature from $60^{\circ} \mathrm{C}$ to $99^{\circ} \mathrm{C}$ at ramping increments from $0.1^{\circ} \mathrm{C} / \mathrm{s}$. The HRM analysis was carried out using the Eco software (version 3.0) with normalization regions between $79.1-79.4^{\circ} \mathrm{C}$ and $87.1-87.4^{\circ} \mathrm{C}$. A difference melting curve was produced with $E$. ortleppi as baseline.

To validate HRM-cox 1 profiles, 58 isolates of Echinococcus spp. collected from hydatid cysts of bovine livers and lungs were analyzed. DNA from protoscoleces and germinal layer were used to evaluate the usefulness of this technique to differentiate Echinococcus species. The HRM was carried out using Rotor-gene Q 2plex System (Roche ${ }^{\circ}$ ) as described above, in attempt to show that this method is reproducible with alternative systems. As reference curves of HRM, a known sample for E. granulosus and $E$. ortleppi was used.

One positive amplicon of each sample derived from PCR-HRM that displayed distinct curve shapes were sequenced. Sequence quality assessment and assembly was performed using DNAStar software (version 8.1.3). After PCR amplification, confirmation of the species was performed by a homology search against reference sequences using the Basic Local Alignment Search Tool (BLAST) program hosted by the National Centre for Biotechnology Information (http://www.ncbi.nlm.nih.gov).

A DNA fragment of $444 \mathrm{bp}$ from the cox 1 mitochondrial gene was amplified in all analyzed samples and no amplification was observed in the control reactions (NTCs). With SYBR Green Tm-based and HRM analyses, very low Tm variability was observed (Table 1 ). E. granulosus and E. ortleppi melting curves showed a difference in

Table 1 Species examined, the samples location, host and the number of isolates

\begin{tabular}{|c|c|c|c|c|c|c|c|c|c|c|c|}
\hline \multirow[b]{2}{*}{ Species } & \multirow[b]{2}{*}{ Location } & \multirow[b]{2}{*}{ Host } & \multicolumn{3}{|c|}{ SYBR Green Tm-based } & \multicolumn{3}{|c|}{ HRM analysis } & \multicolumn{3}{|c|}{ Validation test } \\
\hline & & & $\begin{array}{l}\text { Number of } \\
\text { isolates }\end{array}$ & $\mathrm{Tm}$ & SD & $\begin{array}{l}\text { Number of } \\
\text { isolates }\end{array}$ & $\mathrm{Tm}$ & SD & $\begin{array}{l}\text { Number of } \\
\text { isolates }\end{array}$ & $\mathrm{Tm}$ & SD \\
\hline E. ortleppi & Southern Brazil & Bovine & 18 & 82.70 & 0.08 & 6 & 83.35 & 0.02 & 32 & 81.70 & 0.03 \\
\hline E. granulosus & Southern Brazil & Bovine & 15 & 84.04 & 0.13 & 4 & 83.72 & 0.07 & 26 & 82.30 & 0.05 \\
\hline E. oligarthrus & Northern Brazil & Agouti & 3 & 82.56 & 0.05 & 3 & 82.70 & 0.07 & - & - & - \\
\hline E. vogeli & Northern Brazil & Paca & 2 & 83.30 & 0.05 & 2 & 84.10 & 0.14 & - & - & - \\
\hline E. multilocularis & Europe & Monkey & - & - & - & 6 & 82.70 & 0.07 & - & - & - \\
\hline E. canadensis (G7) & Southern Brazil & Pig & - & - & - & 2 & 82.05 & 0.03 & - & - & - \\
\hline T. hydatigena & Southern Brazil & Pig & - & - & - & 3 & 81.95 & 0.07 & - & - & - \\
\hline
\end{tabular}

The melting temperatures (Tm) and standard deviations (SD) obtained in the SYBR Green Tm-based, HRM analyses and validation test are shown. 
the $\mathrm{Tm}$ of $1.34^{\circ} \mathrm{C}$ (Table 1; Figure 1A). Likewise, E. vogeli and $E$. oligarthra showed a difference of $0.74^{\circ} \mathrm{C}$ (Table 1; Figure $1 \mathrm{C}$ ). The differences in the $\mathrm{Tm}$ were at least nine and eight times higher than the respective standard deviation (SD), respectively (Table 1). These results refer to the total number of samples used, although in Figure 1, for comparison, only the curves of the isolates that were also used in the HRM approach are presented. Similarly, the Tm obtained from the HRM analysis, showed a difference of $0.37^{\circ} \mathrm{C}$ between $E$. granulosus and E. ortleppi and a difference of $1.40^{\circ} \mathrm{C}$ between E. vogeli and E. oligarthra. In this analysis, the SDs were five and ten times lower than the differences in Tm, respectively (Table 1; Figure 1B and D).
In the HRM analysis, a specific profile for each species analyzed was observed in both the standard and the difference curve (Figures $2 \mathrm{~A}$ and $\mathrm{B}$, respectively). Despite the close Tm value observed for some species, the HRM profiles provide a clear and undoubted discrimination among them. See, for example, the comparisons between E. multilocularis and E. ortleppi or between E. canadensis (G7) and E. oligarthra (Table 1; Figure $2 \mathrm{~A}$ and $\mathrm{B}$ ). In our validation test, from the HRM profiles of the cox1 gene, thirty-two samples were correctly identified as E. ortleppi and twenty-six of the samples obtained were identified as E. granulosus sensu stricto (G1) (Table 1; Figure 2C). The results obtained by PCR-HRM for all the tested samples

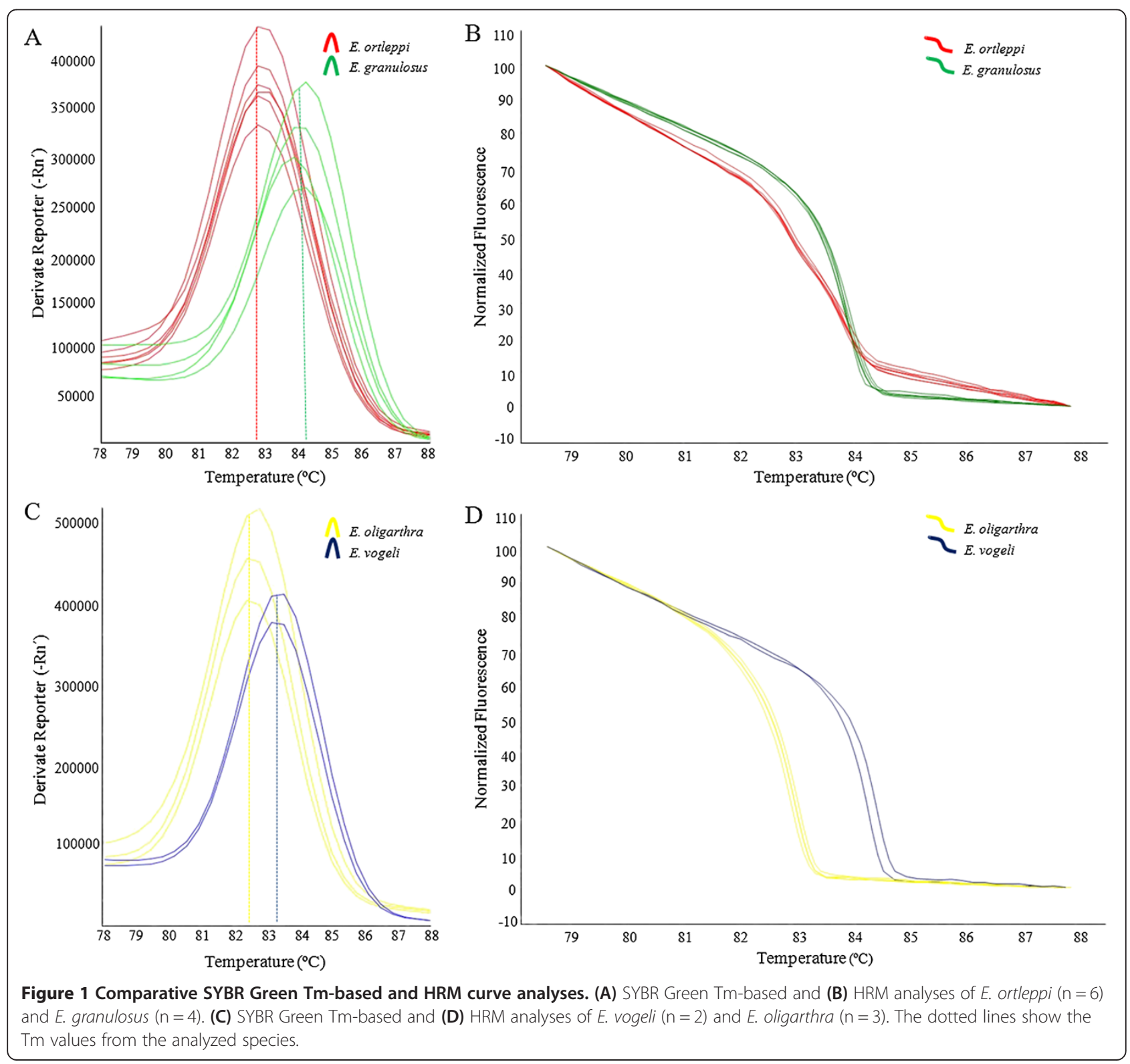




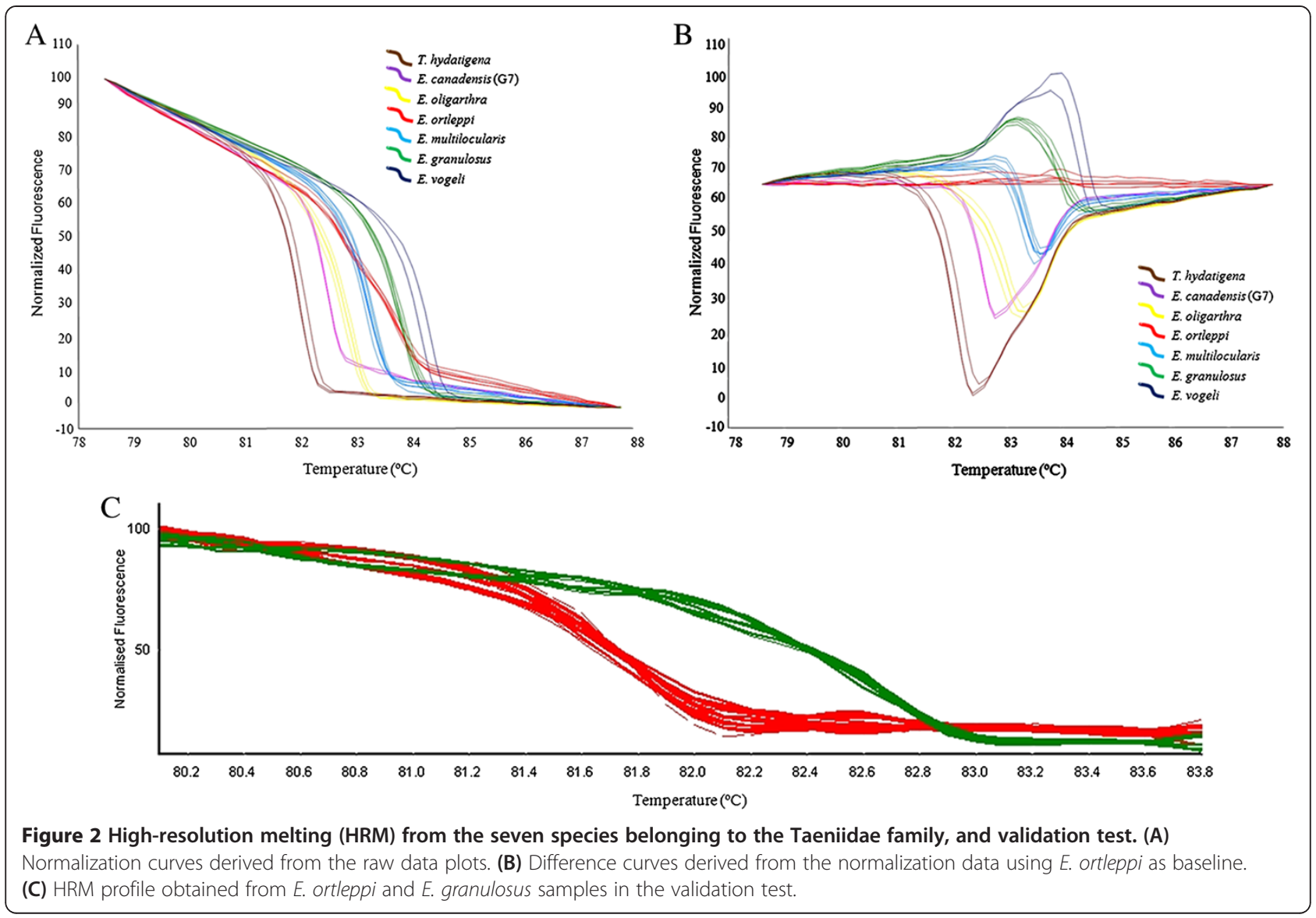

were confirmed by sequencing the amplicons. BLASTn analysis showed identity values greater than $99 \%$ for all samples.

We show, for the first time, that it is possible to distinguish E. granulosus from E. ortleppi as well as E. vogeli from $E$. oligarthra using the Tm obtained from the melting analysis of cox1. Furthermore, we compared this species with E. multilocularis, E. canadensis and T. hydatigena, and discriminated them by HRM, that is a useful and advantageous method that can be routinely employed in endemic regions of echinococcosis. This observation will be useful for additional HRM analyses of the Taeniidae family and, thus, will serve as a basis for subsequent interpretations.

The development of fast and effective tools for Echinococcus species identification has been the subject of numerous studies. For instance, morphological differences and the cut-off value for adult and larval hook were determined to distinguish E. granulosus sensu lato isolates $[20,21]$. However, the larval rostellar hook morphometry method is dependent on the presence of protoscoleces. In contrast, HRM analyses allow the use of DNA extracted from any parasite material as we showed in the validation test (Figure 2C).
In an attempt to implement an Echinococcus genotyping tool, a multiplex PCR (mPCR) test was used, using eleven pairs of primers, and it successfully differentiated the species of the Echinococcus granulosus complex [22]. Here, we present a technique that only requires a single pair of primers that amplify the cox1 gene, providing a quick, closed-tube and gel-free detection method for species belonging to the Echinococcus genus (Figure 2A and $\mathrm{B}$ ). In our procedure, the identification of the species of the genus Echinococcus took approximately 6 hours. Recently, the application of HRM analysis was reported for genotyping E. granulosus sensu lato in Iran to distinguish G6 from the G1 and G3 genotypes, but it did not show good results in distinguishing G1 from G3 [23].

In conclusion, we propose the use of HRM of the cox1 gene as a routine method to distinguish Echinococcus species in epidemiological surveys or in basic research (Figure 2). This method may also be applied to identify other species belonging to the Taeniidae family. Finally, we believe that the HRM method could be implemented using a smaller amplicon product when the goal is to identify minor differences, such as in the case of closely related genotypes. 


\section{Abbreviations}

HRM: High-resolution melting; NTCs: Non-template controls; BLAST: Basic local alignment search tool; Tm: Melting temperature; SD: Standard deviation.

\section{Competing interests}

There are no conflicts of interest

\section{Authors' contributions}

GBS participated in the design of the study, and in the HRM experiments. Wrote the manuscript. SME participated in the SYBR Green Tm-based experiments, helped to draft the manuscript. HBF participated in the design of the study and helped to draft the manuscript. RM participated in HRM experiments and helped to draft the manuscript. AZ participated in the design of the study and helped to draft the manuscript. All authors read and approved the final version of the manuscript

\section{Acknowledgments}

This work was supported by CAPES and CNPq. G.S.B. and S.M.E. are recipient of fellowships from CAPES and CNPq, respectively. We would like to express our thanks to Dr. Karen Haag for providing access to her Echinococcus DNA database and Dr. Itabajara Vaz da Silva Junior and MSc. Daiani Oldiges for providing access to Rotor-gene Q 2plex.

\section{Author details}

${ }^{1}$ Programa de Pós-Graduação em Biologia Celular e Molecular, Universidade Federal do Rio Grande do Sul, Caixa Postal 15005, CEP 91501-970, Porto Alegre, RS, Brazil. ${ }^{2}$ Programa de Pós-Graduação em Genética e Biologia Molecular, Universidade Federal do Rio Grande do Sul, Caixa Postal 15053, CEP 91501-970, Porto Alegre, RS, Brazil. ${ }^{3}$ Centro de Biotecnologia, Universidade Federal do Rio Grande do Sul, CEP 91501-970, Porto Alegre, RS, Brazil.

Received: 11 October 2013 Accepted: 5 November 2013

Published: 14 November 2013

\section{References}

1. Nakao M, McManus DP, Schantz PM, Craig PS, Ito A: A molecular phylogeny of the genus Echinococcus inferred from complete mitochondrial genomes. Parasitology 2007, 134:713-722

2. Nakao M, Lavikainen A, Yanagida T, Ito A: Phylogenetic systematics of the genus Echinococcus (Cestoda: Taeniidae). Int J Parasito/ 2013, 43:1017-1029.

3. Xiao N, Qiu J, Nakao M, Li T, Yang W, Chen X, Schantz PM, Craig PS, Ito A: Echinococcus shiquicus, a new species from the Qinghai-Tibet plateau region of China: discovery and epidemiological implications. Parasitol Int 2006, 55:233-236.

4. Hüttner M, Nakao M, Wassermann T, Siefert L, Boomker JDF, Dinkel A, Sako Y, Mackenstedt U, Romig T, Ito A: Genetic characterization and phylogenetic position of Echinococcus felidis (Cestoda: Taeniidae) from the African lion. Int J Parasito/ 2008, 38:861-868.

5. Balbinotti H, Santos GB, Badaraco J, Arend AC, Graichen DA, Haag KL, Zaha A: Echinococcus ortleppi (G5) and Echinococcus granulosus sensu stricto (G1) loads in cattle from Southern Brazil. Vet Parasitol 2012, 188:255-260.

6. D'Alessandro A, Rausch RL: New aspects of neotropical polycystic (Echinococcus vogeli) and unicystic (Echinococcus oligarthrus) echinococcosis. Clin Microbiol Rev 2008, 21:380-401.

7. Loos-Frank B: An up-date of Verster's (1969) Taxonomic revision of the genus Taenia Linnaeus (Cestoda) in table format. Syst Parasitol 2000, 45:155-183.

8. Nakao M, Lavikainen A, Iwaki T: Molecular phylogeny of the genus Taenia (Cestoda: Taeniidae): proposals for the resurrection of Hydatigera Lamarck, 1816 and the creation of a new genus Versteria. Int J Parasitol 2013, 43:427-437.

9. Lin JH, Tseng CP, Chen YJ, Lin CY, Chang SS, Wu HS, Cheng JC: Rapid differentiation of influenza A virus subtypes and genetic screening for virus variants by high-resolution melting analysis. J Clin Microbiol 2008, 46:1090-1097.

10. Gago S, Zaragoza Ó, Cuesta I, Rodríguez-Tudela JL, Cuenca-Estrella M, Buitrago MJ: High resolution melting analysis for identification of the Cryptococcus neoformans-Cryptococcus gattii complex. J Clin Microbiol 2011, 49:3663-3666.
11. Nasereddin A, Jaffe CL: Rapid diagnosis of Old World Leishmaniasis by high-resolution melting analysis of the 7SL RNA gene. J Clin Microbiol 2010, 48:2240-2242.

12. Wongkamchai S, Monkong N, Mahannol P, Taweethavonsawat $P$, Loymak S, Foongladda S: Rapid detection and identification of Brugia malayi, $B$. pahangi, and Dirofilaria immitis by high-resolution melting assay. Vector Borne Zoonotic Dis 2013, 13:31-36.

13. Higuera SL, Guhl F, Ramírez JD: Identification of Trypanosoma cruzi Discrete Typing Units (DTUs) through the implementation of a High-Resolution Melting (HRM) genotyping assay. Parasit Vectors 2013, 6:112.

14. Peña VH, Fernández GJ, Gómez-Palacio AM, Mejía-Jaramillo AM, Cantillo O, Triana-Chávez O: High-resolution melting (HRM) of the cytochrome B gene: a powerful approach to identify blood-meal sources in Chagas disease Vectors. PLoS Negl Trop Dis 2012, 6:e1530.

15. Haag KL, Alves-Junior L, Zaha A, Ayala FJ: Contingent, non-neutral evolution in a multicellular parasite: natural selection and gene conversion in the Echinococcus granulosus antigen $\mathrm{B}$ gene family. Gene 2004, 333:157-167.

16. Bowles J, Blair D, McManus DP: Genetic variants within the genus Echinococcus identified by mitochondrial DNA sequencing. Mol Biochem Parasitol 1992, 54:165-173.

17. Haag KL, Gottstein B, Ayala FJ: The EG95 antigen of Echinococcus spp. contains positively selected amino acids, which may influence host specificity and vaccine efficacy. PLOS ONE 2009, 4:e5362.

18. Gudnason H, Dufva M, Bang DD, Wolff A: Comparison of multiple DNA dyes for real-time PCR: effects of dye concentration and sequence composition on DNA amplification and melting temperature. Nucleic Acids Res 2007, 35:e127.

19. Eischeid AC: SYTO dyes and EvaGreen outperform SYBR Green in real-time PCR. BMC Res Notes 2011, 4:263.

20. De ML, Takano K, Brochado JF, Costa CV, Soares AG, Yamano K, Yagi K, Katoh Y, Takahashi K: Infection of humans and animals with Echinococcus granulosus (G1 and G3 strains) and E. ortleppi in Southern Brazil. Vet Parasitol 2011, 177:97-103.

21. Soriano SV, Pierangeli NB, Pianciola LA, Mazzeo M, Lazzarini LE, Debiaggi MF, Bergagna HF, Basualdi JA: The optimum cut-off value to differentiate Echinococcus granulosus sensu stricto from other species of $E$. granulosus sensu lato using larval rostellar hook morphometry. J Helminthol 2013, 10:1-8.

22. Boubaker G, Macchiaroli N, Prada L, Cucher MA, Rosenzvit MC, Ziadinov I, Deplazes P, Saarma U, Babba H, Gottstein B, Spiliotis M: A multiplex PCR for the simultaneous detection and genotyping of the Echinococcus granulosus complex. PLoS Negl Trop Dis 2013, 7:e2017.

23. Rostami S, Talebi S, Babaei Z, Sharbatkhoti M, Ziaali N, Rostami H, Harandi MF: High resolution melting technique for molecular epidemiological studies of cystic echinococcosis: differentiating G1, G3, and G6 genotypes of Echinococcus granulosus sensu lato. Parasitol Res 2013, 112:3441-3447.

doi:10.1186/1756-3305-6-327

Cite this article as: Santos et al:: Rapid detection of Echinococcus species by a high-resolution melting (HRM) approach. Parasites \& Vectors 2013 6:327

\section{Submit your next manuscript to BioMed Central and take full advantage of:}

- Convenient online submission

- Thorough peer review

- No space constraints or color figure charges

- Immediate publication on acceptance

- Inclusion in PubMed, CAS, Scopus and Google Scholar

- Research which is freely available for redistribution 